\title{
Robot Dancer for Activities with People with Down Syndrome
}

\author{
Jardel Candido Marques \\ Pontifícia Universidade Católica \\ de Goiás, PUC Goiás \\ Goiânia, Brasil \\ Juliana Santos de Souza \\ Hannum \\ Pontifícia Universidade Católica \\ de Goiás, PUC Goiás \\ Goiânia, Brasil
}

\author{
Kárita Cecília Rodrigues \\ Silva \\ Pontifícia Universidade Católica \\ de Goiás, PUC Goiás \\ Goiânia, Brasil \\ Edson Douglas Fernandes \\ de Moraes Santos \\ Pontifícia Universidade Católica \\ de Goiás, PUC Goiás \\ Goiânia, Brasil
}

\author{
Ariane Ruben Calaça Di \\ Menezes \\ Pontifícia Universidade Católica \\ de Goiás, PUC Goiás \\ Goiânia, Brasil \\ Talles Marcelo Gonçalves \\ de Andrade Barbosa \\ Pontifícia Universidade Católica \\ de Goiás, PUC Goiás \\ Goiânia, Brasil
}

\begin{abstract}
People with Down syndrome have some physical and intellectual characteristics, that can cause motor and cognitive restrictions. The sociable robot must be able to interact with people in a reciprocal way, understanding and expressing attitudes, behaviors, feelings, and emotions. It is an observational, descriptive, and exploratory study containing field research. The Alfadown project an extension offered by PUC-Goiás made it possible to conduct the testing of the robot dancer with people that have SD. They were instructed to understand the proposed activity. First, the volunteer was positioned in front of the robot to begin the test execution. The same should mimic the movements and perform the commands issued by the robot. In this way, variables such as interest, visual contact, dissatisfaction, indifference, attention, and interaction with the robot were investigated and evaluated through the application of a questionnaire to assess the activity.
\end{abstract}

\section{General Terms}

Down's syndrome, social robot, dance.

\section{Keywords}

Down's syndrome, social robot, dance.

\section{INTRODUCTION}

Down syndrome (DS) is a genetic anomaly that has some physical and behavioral characteristics. Some of these characteristics are cognitive deficits, behavioral disorders, language, and motor difficulties due to muscular hypotonia. Muscle hypotonia is the lack of muscle tone, which makes the individual with SD more flexible, with weaker muscles and slower movements. The limitations of people with DS are undefined, as such, opportunities must be offered, and their potential discovered [1].

The Alfadown extension project of PUC-Goiás offers free activities for the development of social skills, and digital literacy for people with DS, guiding them in being the protagonist of their own story. In this way, specific activities and technological tools are planned and implemented to support, for example, applications for the mobile platform [2]. In addition, tools for automatic and online evaluation of the participant, through biofeedback, and systems that offer augmented reality for the execution of activities for literacy. It can be said that currently, the use of social robots is being investigated.

Tega [6] is a robotic platform designed to interact with children through literacy applications during storytelling. PopBots [7] is another example of a sociable robot that is designed to help children learn about artificial intelligence (AI). The social robot can be a learning partner and programmable artifact, while also being effective in helping understand the concepts of AI.

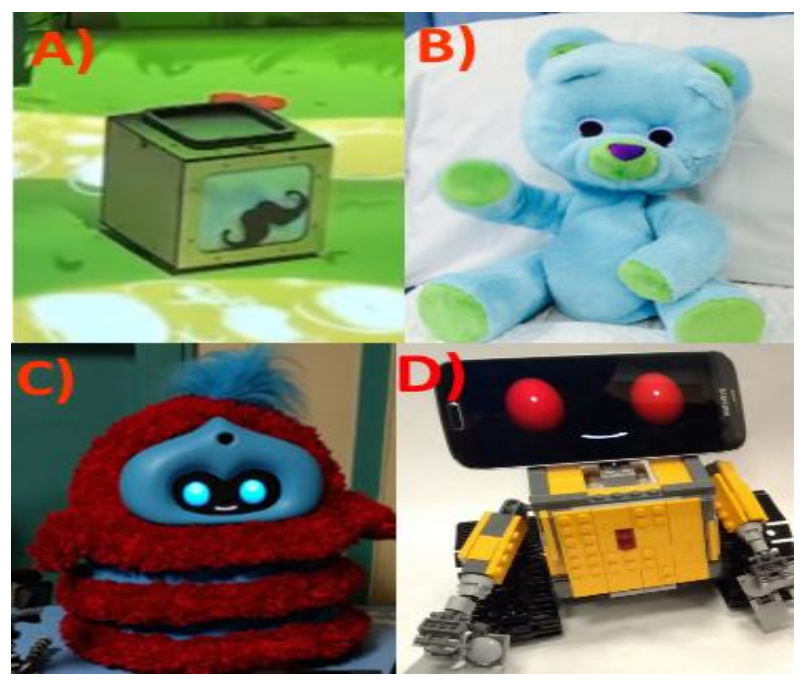

Fig. 1. Sociable robots (a), AlphaBot [4] (b), Huggable [5] (c), Tega [6] (d), PopBots [7].

This work presents a robot dancer built to assist the execution of psychomotor activities offered to the students of the Alfadown project. This robot enables the creation of a playful scene through the use of lights and music. It expresses emotions and behaviors through graphic elements, voice commands, and movements performed in harmony with the music.

For the study, requirements were implemented and evaluated that helped to describe the interaction between people with DS and sociable robots. It should be noted that after reviewing the literature, there were no records of other studies that evaluated this type of interaction through training and 
entertainment activities. It is an observational, descriptive, and exploratory study containing field research. A selfevaluation questionnaire was used as an instrument for data collection. This work is part of the project titled "Down Syndrome and Autistic Spectrum Disorder: Researching Families to Understand the Impact of Disability on Parents and the Support Offered" authorized by the Research Ethics Committee through the Certificate of Presentation for Ethical Assessment (CAAE): 51159415.3.0000.0037.

\section{MATERIALS AND METHODS}

The construction of the robot was based on the incremental bottom-up model. This model was used for the refinement of the requirements, the customization of components, and technological resources available in the embedded systems laboratory at PUC Goiás. Figure 2 shows a diagram of the robot development process. The hardware development process had as objectives the analysis of the torque, current drain operation of the motors together with the mobile structure of the robot, and design the whole electrical scheme to feed the electronic devices of the robot.

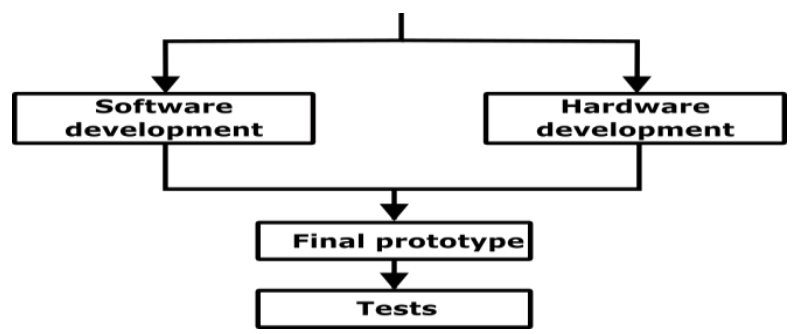

Fig. 2. Development process

Together with the method mentioned above, occurs the software development process, which is responsible for the movement of the robot. The same was developed by two types of controls, one of autonomous form, and another one of a manual kind. The robot was programmed to move autonomously. It contains a library called Arduino_FreeRTOS.h [8] for the Atmel ARV microcontrollers. FreeRTOS [9] is an operating system for embedded devices. The library was implemented in this work based on advantages related to the ease of modifying, checking code, and optimizing CPU usage.

Figure 3 shows the automaton that represents the behavior of the robot during the music. Each state of the automaton corresponds to the action performed. The transitions represent the time the robot waits to complete the next action during the song. The "Start" state is where the robot remains to make the first move. The following state "Forward" is the first movement to be performed, in that state the robot moves forward. The next state "Back" the robot moves back, and in the last state "Rotate" the robot makes a spinning movement on its own axis of $360^{\circ}$.

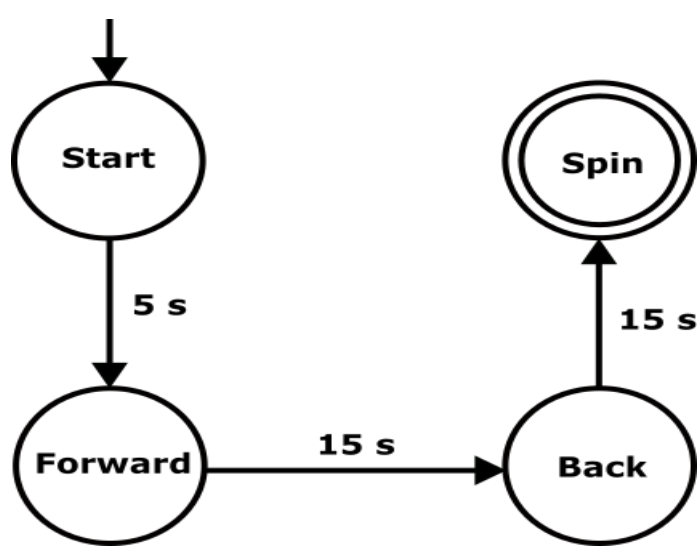

Fig. 3. The actions of the robot

A Bluetooth communication module connected to the microcontroller of the robot is used for manual control. The module received information from a connected device.

Figure 4 shows the Arduino Remote LITE application [10] responsible for sending information to the robot's Bluetooth module. Thus, by pressing the directional buttons of the application interface, it is possible to control the movements of the robot.

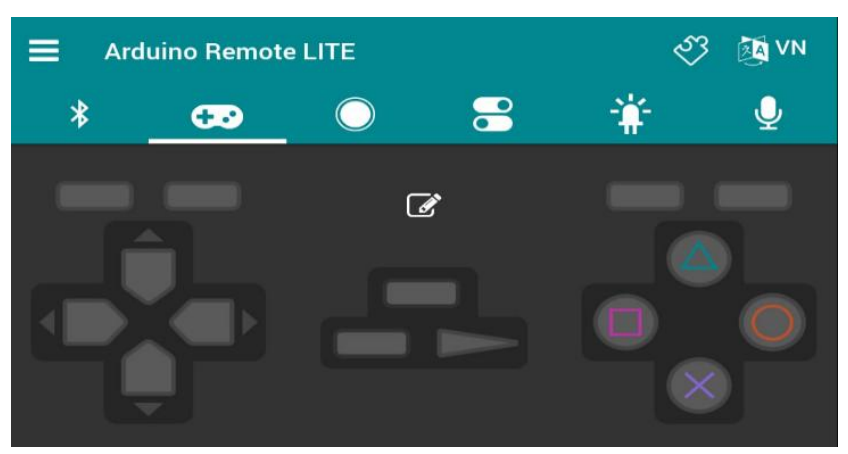

Fig. 4. Arduino Remote LITE application interface

\section{PROTOTYPE}

Figure 5 illustrates the block diagram of the robot containing all the features and their relationship. The microcontroller is responsible for sending signals to the drivers that drive the motors. It also receives information from the sensors and Bluetooth module. The batteries are responsible for powering the entire electrical part of the robot, while also having a voltage inverter providing an $\mathrm{AC}$ voltage output.

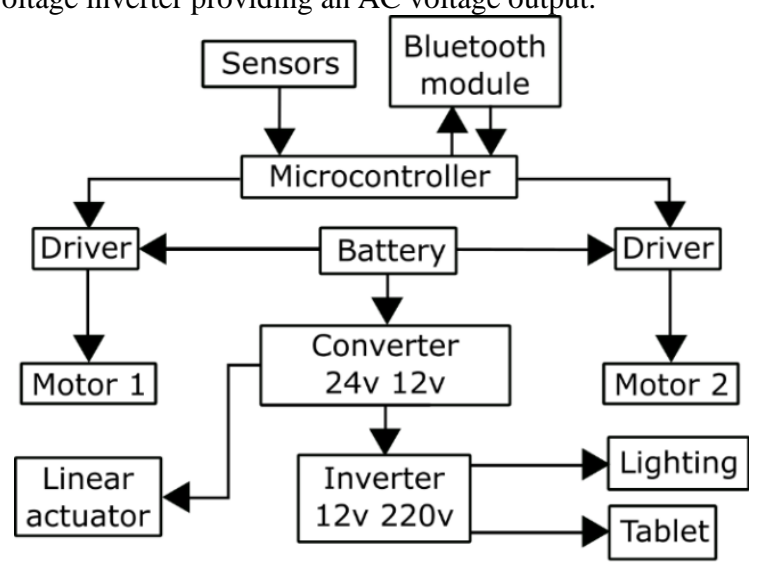

Fig 5. Block diagram of the robot 
Figure 6 shows the final prototype of the robot. The highlighted item A shows the tablet responsible for displaying an interface that changes according to the rhythm of the music. Item B is the light projector, which makes a projection of light on the floor, creating a dance scene. Item $\mathrm{C}$ is a linear actuator. It is a device that reduces and increases the length by moving the tablet.

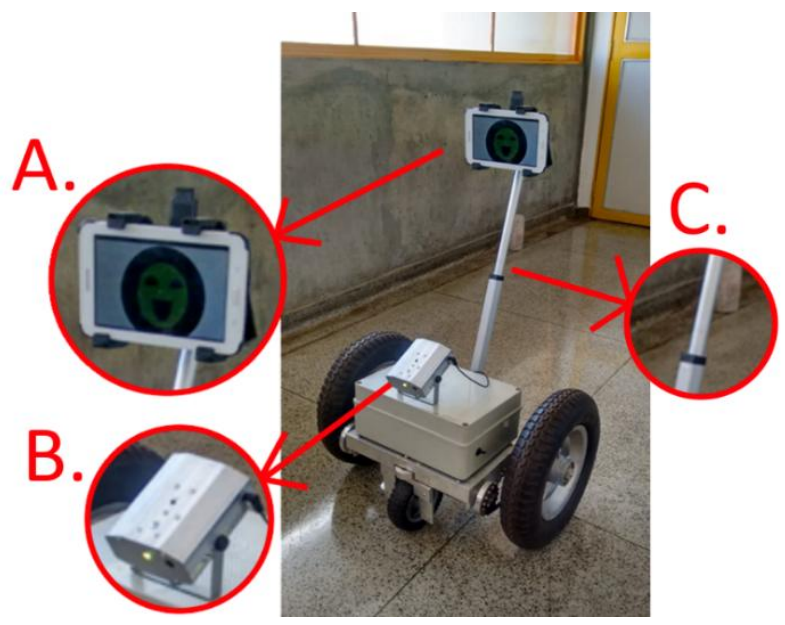

Fig. 6. Final prototype

\section{TESTS}

The process of testing is illustrated by the diagram in Figure 7. For the application of the research, evaluators verified the volunteer's interest to continue. Otherwise, the volunteer would return to the routine activities offered by the Alfadown project. It is worth mentioning that none of the selected participants showed any embarrassment or disinterest in continuing. The consent for each of the volunteers was recorded in an audio file. Volunteers unable to understand were excluded from the study. The tests were performed individually in a reserved room to avoid embarrassment and guarantee the confidentiality of the research participant. In addition to the researchers, only the parents of each participant were invited to attend.

The volunteer was recruited and presented to the robot. In order to perform the test, people with DS were instructed to understand the proposed activity. First, to begin the test execution, the volunteer was positioned in front of the robot. The volunteer should mimic the movements and perform the commands issued by the robot: "Go forward", "Back", and "Rotate". The volunteer's evaluation questionnaire was completed in conjunction with the testing. In the end, the volunteer would be re-assigned to the routine activities offered by the Alfadown project.

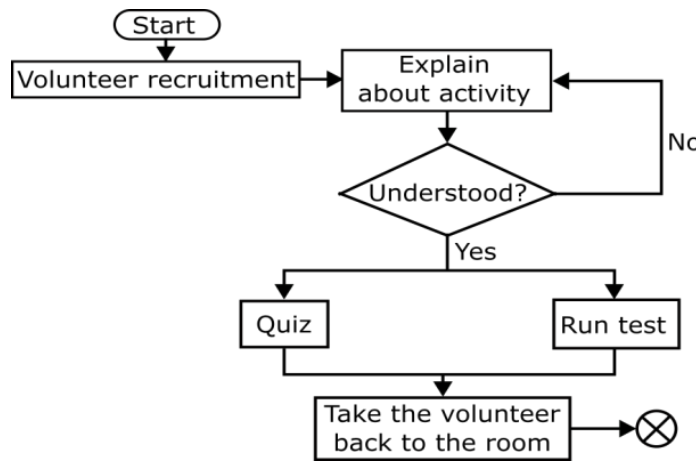

Fig. 7. Activity diagram
Figure 8 shows the evaluation questionnaire completed during the execution of each test. The survey contains data such as age, gender, and research questions. The first question presents the three commands issued by the robot. The volunteer was observed in each one of the sound commands emitted by the robot during the accomplishment of the activity. If the volunteer executed the command issued by the robot in a suitable form, the "Yes" would be marked. Otherwise, "No" was selected. The second question presents the interest of the volunteer in making physical contact with the robot. The third question asks if the volunteer maintained visual contact with the robot during the execution of the activity. The fourth question verifies if the volunteer had an interest in carrying out the proposed activity, while issue five observed the indifference by analyzing the emotions of the volunteer. The last question is regarding the attention of the volunteer, during the commands emitted by the robot, and in the explanation of the activity to be performed.

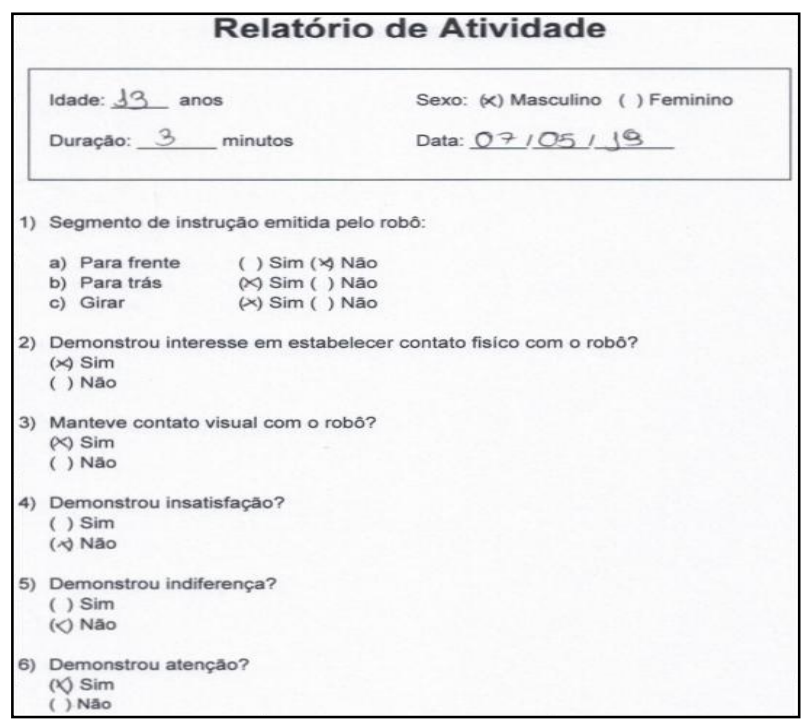

Fig. 8. Activity assessment questionnaire.

\section{TEST ENVIRONMENT}

Figure 9 illustrates the testing environment, which was used for data collection. It is a private and heated room located in PUC Goiás in the same building where the activities of the Alfadown project takes place. The image was captured during the execution of the tests, showing a participant performing the proposed activity with the robot.

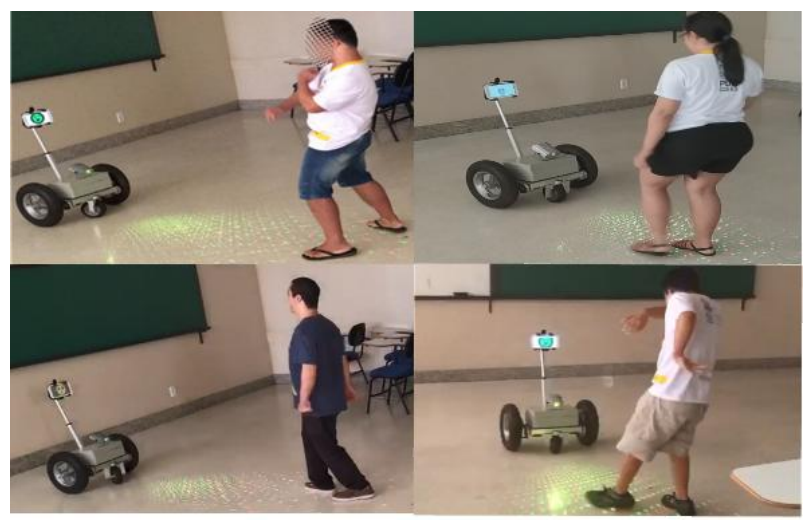

Fig. 9. The implementation of the tests. 


\section{RESULTS AND DISCUSSIONS}

Figure 10 shows the results of the execution of the commands emitted by the robot. The columns in red represent the percentage of people who did not execute the command issued by the robot. The columns in blue represent the percentage of people who did run the command correctly. Activity 1 was represented by the go forward command, activity 2 the go back command, and activity 3 the turn command. In this study, 26 volunteers aged between 10 and 51 years old participated, 16 men and ten women. During testing, there was a significant increase in volunteers who were able to perform activities 2 and three emitted by the robot. Thus, demonstrating a greater understanding of the proposed activity, because knowing the voice and the movement of the robot during the first activity suggests the facilitation of the agreement and execution of the commands in the next events. In general, the performed tests lasted 3 minutes for each participant.

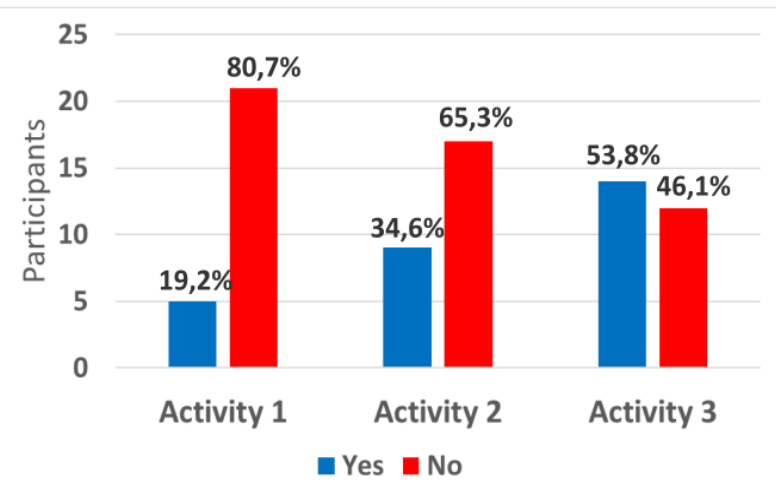

Fig. 10. Graph of the results of the commands emitted by the robot

Figures 11 and 12 illustrate the probabilities calculated on the variables obtained through the questionnaire quoted in the previous session. The variables physical contact, visual contact and attention had on average a percentage of $83.3 \%$ revealing signs that strengthen the hypothesis that the use of the robot can help in the execution of other types of activities such as literacy.

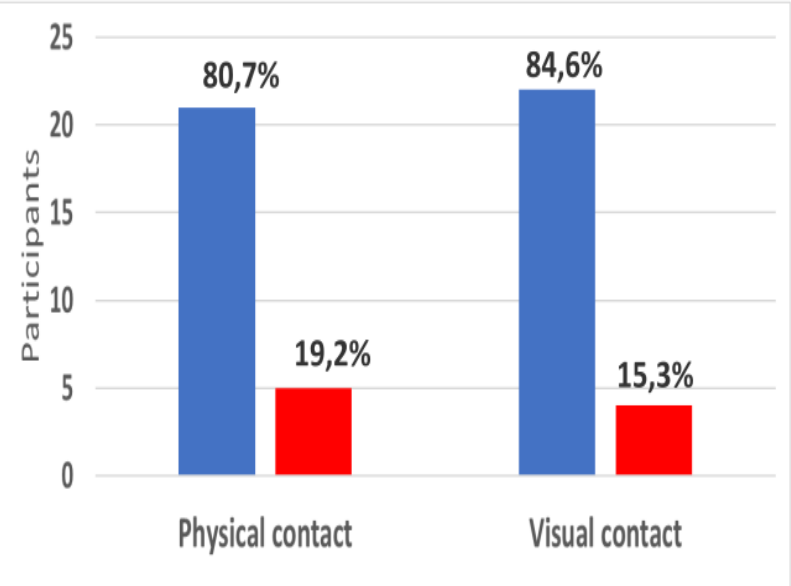

-Yes $\mathbf{n}$ No

Fig. 11. Graph of the results of physical contact and visual contact

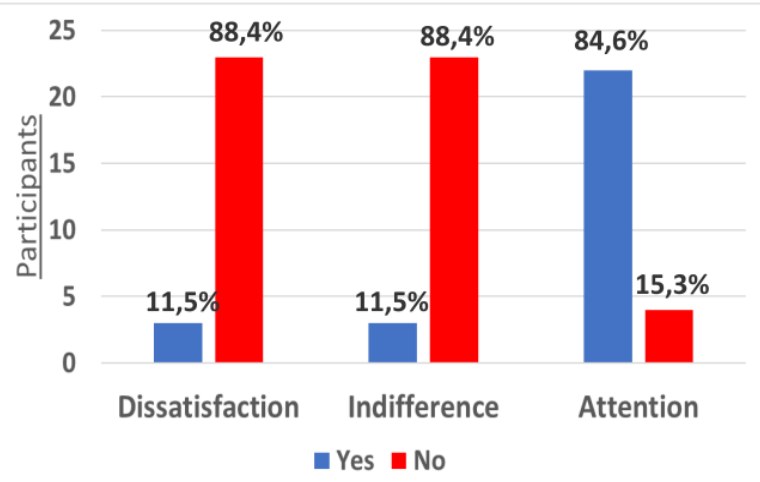

Fig. 12. Graph of the results of dissatisfaction, indifference, and attention

Table 1 shows the number of people who executed the commands, and it was divided into genres. Table 2 shows the number of people who completed the activities which were separated by age groups. The age groups were as follow: children between 0 and ten years of age, between 12 and 17 years, and adults between 18 and 51 years. It can be said that the group of adults performed better compared to the groups of children and adolescents.

Table 1: Divided By Genres

\begin{tabular}{|c|c|c|c|c|c|c|c|}
\hline & \multicolumn{2}{|c|}{ Combindo 1} & \multicolumn{2}{|c|}{ Comando 2} & \multicolumn{2}{|c|}{ Comando 3} & \\
\hline Gentes & Completed & $\%$ & Completed & $\%$ & Completed & $\%$ & Total \\
\hline M: & 4 & 25 & 5 & 31,25 & 9 & 56,25 & 16 \\
\hline Female & 1 & 10 & 4 & 40 & 5 & 50 & 10 \\
\hline
\end{tabular}

Table 2: Age Groups

\begin{tabular}{|c|c|c|c|c|c|c|c|}
\cline { 2 - 8 } & \multicolumn{2}{|c|}{ Command 1 } & \multicolumn{2}{c|}{ Command 2 } & \multicolumn{2}{c|}{ Command 3 } & \\
\cline { 2 - 8 } & Completed & $\%$ & Completed & $\%$ & Completed & $\%$ & Total \\
\hline $\begin{array}{c}\text { Ahildren (0-11) } \\
\text { Teenager (12-17) }\end{array}$ & 1 & 8,33 & 3 & 25,00 & 7 & 58,33 & 12 \\
\hline Adult (18-51) & 4 & 28,57 & 6 & 42,86 & 7 & 50 & 14 \\
\hline
\end{tabular}

\section{CONCLUSIONS}

This work presents a robotic platform to interact with people with DS. The use of the robot can increase interest and facilitate the person's involvement during activity through the interaction of the robot with the individual. However, for the exploratory purpose of this research, it is not possible to affirm that the use of a sociable robot produces better results compared to the human being. For this, it is necessary to have a longitudinal study with the use of a control group. Future works include a plan to use the robot to perform movements according to voice command issued by humans. Also, including the use of a biofeedback tool to evaluate the interaction automatically. 


\section{REFERENCES}

[1] Vanessa Helena Santana Dalla Déa, Edison Duarte. "Síndrome de Down: informações, caminhos e histórias de amor." - São Paulo: Phorte, 2009.

[2] Sousa, M.V., Ramos, D., Castro, L., Cruz, M., Hannum, J. E Barbosa, T.M. 2017."An application to assist people with down syndrome in Literacy Learning". "Lori's Help: um aplicativo para auxílio na alfabetização de pessoas com Síndrome de Down." Revista Brasileira de Computação Aplicada. 9, 2 (jul. 2017), 2-13, in press.

[3] Cynthia L. Breazeal Designing Sociable Robots, MIT Press, Cambridge, MA, 2002

[4] D. Robert, C. Breazeal (2012) Blended reality characters, in press.

[5] Jeong, Sooyeon, ET AL. "A social robot to mitigate stress, anxiety, and pain in pediatric hospital care." Proceedings of the Tenth Annual ACM/IEEE International Conference on Human-Robot Interaction
Extended Abstracts. ACM, 2015, in press.

[6] Kory Westlund, J. M., Lee, J., Plummer, L., Faridia, F., Gray, J., Berlin, M., Quintus-Bosz, H., Harmann, R., Hess, M., Dyer, S., dos Santos, K., Adalgeirsson, S., Gordon, G., Spaulding, S., Martinez, M., das, M., Archie, M., Jeong, S., \& Breazeal, C. (2016). Tega: A Social Robot, in press.

[7] Randi Williams, Hae Won Park, Lauren Oh, Cynthia Breazeal. 2019. PopBots: Designing an Artificial Intelligence Curriculum for Early Childhood Education. In Proceedings of the 9th Symposium on education advances in artificial intelligence (eaai '19). aaai, menlo park, ca, USA, in press.

[8] Arduino_FreeRTOS_Library available in: < https://github.com/feilipu/Arduino_FreeRTOS_Library/b lob/master/src/Arduino_FreeRTOS.h >.

[9] Quality RTOS \& Embedded Software. available in: < https://www.freertos.org/RTOS.html 